\title{
Morbidity and mortality after autotransfusion following open heart surgery
}

\author{
Sushil Kumar Singh • Tushar Goyal • Vijayant Devenraj • \\ Tulika Chandra • Brij Bihari Kushwaha • Santosh Gupta • \\ Vivek Tewarson • Sarvesh Kumar • Shailendra Kumar
}

Received: 27 February 2013 /Revised: 17 April 2013 /Accepted: 13 January 2014 / Published online: 20 March 2014

(C) Indian Association of Cardiovascular-Thoracic Surgeons 2014

\begin{abstract}
Background The technique of 'blood pooling' before the onset of cardiopulmonary bypass (CPB) has been shown to be beneficial as a single technique in patients having elective open heart surgery. We sought to more clearly evaluate the role of intra-operative autologous donation also known as acute normovolemic haemodilution in open heart surgery. Methods The study was conducted in the Department of Cardiothoracic and Vascular Surgery, King George's Medical University, Lucknow, India, in patients who underwent open heart surgery under cardiopulmonary bypass.
\end{abstract}

\author{
S. K. Singh $(\varangle) \cdot$ T. Goyal $\cdot$ V. Devenraj $\cdot$ S. Gupta $\cdot$ V. Tewarson $\cdot$ \\ S. Kumar $\cdot$ S. Kumar \\ Department of Cardiothoracic and Vascular Surgery, King George's \\ Medical University, Lucknow, Uttar Pradesh 226003, India \\ e-mail: doctorsushil@hotmail.com \\ T. Goyal \\ e-mail: drtushargoyal@gmail.com \\ V. Devenraj \\ e-mail: vijayantdevenraj@gmail.com \\ S. Gupta \\ e-mail: santoshhari7@yahoo.co.uk \\ V. Tewarson \\ e-mail: vctewarson@gmail.com \\ S. Kumar \\ e-mail: drsarvesh_kumar462@yahoo.co.in \\ S. Kumar \\ e-mail: skkgmu@yahoo.co.in \\ T. Chandra \\ Department of Transfusion Medicine, King George's Medical \\ University, Lucknow, Uttar Pradesh 226003, India \\ e-mail: tulikachandra@rediffmail.com \\ B. B. Kushwaha \\ Department of Anaesthesiology, King George's Medical University, \\ Lucknow, Uttar Pradesh 226003, India \\ e-mail: brij_kushwaha00634@yahoo.com
}

Autologous blood transfusion was used in all the patients who underwent surgery on CPB since August 2009. Patients were divided into two groups: group I (study group)-patients operated between August 2009 and December 2011 and who received autologous blood and group II (control) - those operated before August 2009 and who did not receive autologous blood transfusion.

Results The post-operative haemoglobin and coagulation profile measured on the first post-operative day differed significantly between the two groups. Intensive care unit (ICU) stay, hospital stay, inotropic support and ventilatory support were significantly less in group 1. Mediastinal drainage was found to be significantly higher in the control group compared to the study group. The mean volume of packed red blood cell, fresh frozen plasma and platelet units transfused per patient in the study group were significantly less than the control group. Conclusion The use of intra-operative autologous blood donation and transfusion improves haemostasis, decreases the post-operative blood loss and improves the post-operative outcome in terms of intensive care unit stay, hospital stay, morbidity and mortality.

Keywords Acute normovolemic haemodilution .

Transfusion · Autologous

\section{Introduction}

Blood conservation in cardiac surgery has continually evolved in response to limitations in the supply of blood products and increased physician and patient awareness of transfusionrelated illness. One of the oldest blood conservation techniques involves the removal of a portion of a patient's blood volume intra-operatively before institution of cardiopulmonary bypass (CPB) and reinfusion of this blood immediately after cardiopulmonary bypass. Known as acute normovolemic 
haemodilution (ANH), acute autologous donation, blood pooling and more recently and perhaps more accurately as intra-operative autologous donation (IAD), this technique was first described for use in cardiac surgery by Dodrill et al. in 1957 [1].

The risks of homologous blood transfusion are welldocumented and include the transmission of infectious disease and the risks of receiving incompatible blood [2]. A variety of blood conservation techniques have evolved to minimize the transfusion requirements for open heart operations [3]. The technique of IAD before the onset of cardiopulmonary bypass has been shown to be beneficial as a single technique in patients having elective open heart surgeries [4].

We sought to more clearly evaluate the role of IAD in open heart surgery under cardiopulmonary bypass in terms of postoperative coagulation profile, bleeding, need for homologous blood transfusion, post-operative recovery, morbidity and mortality.

\section{Material and methods}

The study was conducted in the Department of Cardiothoracic and Vascular Surgery, King George's Medical University, Lucknow, India, in 324 patients who underwent open heart surgery under cardiopulmonary bypass between January 2007 and December 2011.

We started using autologous transfusion in August 2009and used it in all the patients who underwent surgery on CPB. Patients were divided into two group: group I (study group)-patients operated between August 2009 and December 2011 and who received IAD and group II (control) - those operated before August 2009 and who did not receive autologous blood transfusion.

Exclusion criteria for the study were pre-operative haemoglobin less than $9 \mathrm{~g} / \mathrm{dl}$, age more than 80 years, ejection fraction less than $25 \%$, emergency surgeries and presence of severe aortic stenosis, renal failure, cirrhosis or hematologic disorder that could possibly result to post-operative bleeding.

Except for collection and reinfusion of autologous blood, all aspects of pre-operative, intra-operative and post-operative care were identical between groups. All patients were operated by the same surgeon and team. The CPB circuit included a membrane oxygenator and roller pump. In all cases, the circuit was primed with Lactated Ringer's solution and mannitol was added to the prime as per body weight. In all cases, injection aprotinin $(500,000 \mathrm{KIU})$ and injection tranexamic acid $(1 \mathrm{~g})$ were added to the prime. Intermittent antegrade cold blood cardioplegia with moderate systemic cooling (28 to $32{ }^{\circ} \mathrm{C}$ ) was used for all cases. Patients were anti-coagulated before $\mathrm{CPB}$ with $3 \mathrm{mg} / \mathrm{kg}$ of heparin sulphate. Activated clotting time was maintained more than $480 \mathrm{~s}$ before and during cardiopulmonary bypass; protamine sulphate reversal was given in all the patients to achieve the baseline level of ACT at the end of bypass. Blood was added to the pump during cardiopulmonary bypass only if their hematocrit was less than $18 \%$. Our blood conservation protocol for both groups included retransfusion of all oxygenator and tubing blood contents after cardiopulmonary bypass. Banked red blood cells were only used if the haemoglobin was less than $8 \mathrm{~g} / \mathrm{dl}$ post-operatively. Aspirin was stopped 4 days prior to surgery in both groups.

After anaesthetic induction, but before heparinization, $10 \mathrm{ml} / \mathrm{kg}$ blood volume was removed via wide-bore internal jugular venous line into standard citrate-phosphate-dextrose collection bags in group I patients. Systolic blood pressure was maintained greater than $90 \mathrm{mmHg}$ with simultaneous crystalloid infusion through peripheral line during removal. This blood was stored in a reservoir bag and was re-transfused to the patients after cardiopulmonary bypass once the heparin had been neutralized with protamine. The blood was stored at room temperature $\left(25^{\circ} \mathrm{C}\right)$ without agitation until the time of reinfusion. Data was collected from case sheets, intensive care unit (ICU) charts and computerized data sheets. Patient characteristics, pre- and post-operative laboratory investigations, ventilator requirement, inotrope requirement, intensive care unit/hospital stay, post-operative bleeding, fever, wound infection and transfusion requirement were recorded and compared between the two groups. Data was evaluated using SPSS software version 16 (SPSS Inc., Chicago, USA). Unpaired $t$ test was used for continuous variables and chisquare test for non-continuous variables. A ' $p$ value' $<0.01$ was taken as significant. Results were expressed as either percentage of total or mean \pm standard deviation.

\section{Results}

There were 162 patients in each group. The two groups were found to be evenly matched with respect to established risk factors for bleeding and transfusion requirement including age (31.23 \pm 13.49 vs. $31.78 \pm 13.90$ years, $p>0.01)$, sex $(p>0.01)$, height ( $158.36 \pm 13.31$ vs. $157.04 \pm 14.74 \mathrm{~cm}, p>0.01)$, weight $(43.48 \pm 10.20$ vs. $42.4 \pm 10.22 \mathrm{~kg}, p>0.01)$, body surface area $\left(1.37 \pm 0.20\right.$ vs. $\left.1.35 \pm 0.22 \mathrm{~m}^{2}, p>0.01\right)$, bypass time, pre-op creatinine level and procedures(Table 1). Both groups were evenly matched with respect to pre-operative laboratory investigations, and there was no statistical difference between the two groups (Table 2). None of the patients in either group had deranged coagulation profile, liver function or renal function at the time of surgery.

The post-operative laboratory data is listed in (Table 3). Mean post-operative haemoglobin was $10.11 \pm 1.39$ and $8.99 \pm 1.00 \mathrm{~g} / \mathrm{dl}$ in the study and the control group, respective$1 \mathrm{y}$, and this difference was statistically significant $(p<0.01)$. There was no difference in the total leucocyte count between the two groups. Platelet counts on post-operative day 1 were 
Table 1 Procedure wise distribution of cases and controls

\begin{tabular}{lll}
\hline Procedure & Cases $(n=162)$ & Controls $(n=162)$ \\
\hline Double valve replacement & $23(14.2 \%)$ & $25(15.4 \%)$ \\
Mitral valve replacement & $54(33.3 \%)$ & $76(46.9 \%)$ \\
Tetralogy of Fallot repair & $5(3.1 \%)$ & $8(4.9 \%)$ \\
Atrial septal defect closure & $35(21.6 \%)$ & $33(20.4 \%)$ \\
Aortic valve replacement & $28(17.3 \%)$ & $12(7.4 \%)$ \\
Myxoma excision & $5(3.1 \%)$ & $4(2.5 \%)$ \\
Ventricular septal defect closure & $6(3.7 \%)$ & $3(1.9 \%)$ \\
Open mitral valvotomy & 0 & $1(0.6 \%)$ \\
Ruptured sinus of valsalva repair & $3(19 \%)$ & 0 \\
Ebsteins (tricuspid repair) & $2(1.2 \%)$ & 0 \\
Aorto-right ventricular tunnel & $1(0.6 \%)$ & 0 \\
(closure) & & \\
\hline
\end{tabular}

significantly higher in the study group. The post-operative coagulation profile (bleeding time, clotting time and international normalized ratio) measured on the first post-operative day differed significantly $(p<0.01)$ between the two groups.

Duration of inotropic support $(3.09 \pm 3.49$ vs. $11.9 \pm 3.17 \mathrm{~h}$, $p<0.01)$ and ventilatory support $(5.5 \pm 1.55$ vs. $10.75 \pm 2.21 \mathrm{~h}$, $p<0.01$ ) was significantly less in group I. Mediastinal drainage was found to be significantly higher $(234.38 \pm 74.82 \mathrm{vs.}$ $562.47 \pm 118.23 \mathrm{ml}, p<0.01)$ in the control group compared to the study group (Table 4). Owing to the better coagulation profile, less drainage and less inotropic and ventilatory support, the patients in group 1 had shorter ICU stay $(2.26 \pm 0.80$ vs. $3.41 \pm 0.50$ days, $p<.01)$ and were shifted earlier to the ward compared to the control group. Similar difference was found in the hospital stay of the two groups $(5.01 \pm 0.60$ in group I vs. $7.39 \pm 0.60$ days in group II, $p<0.01$ ) (Fig. 1).

In the autologous group, 10 patients $(6.2 \%)$ received homologous red blood cell units in comparison to all 162 patients $(100 \%)$ in the control group. The mean red blood cell units transfused per patient in the cases was $0.06 \pm 0.24 \mathrm{unit} /$ patient in comparison to $2.1 \pm 0.63 \mathrm{unit} / \mathrm{patient}$ in the control group. This difference was found to be

Table 2 Comparison of pre-operative laboratory parameters

\begin{tabular}{llll}
\hline & Case $(n=162)$ & Control $(n=162)$ & $p$ value \\
\hline Haemoglobin $(\mathrm{gm} / \mathrm{dl})$ & $10.86 \pm 1.46$ & $10.84 \pm 1.35$ & 0.87 \\
Total count $/ \mathrm{mm}^{3}$ & $5.42 \pm 0.63$ & $5.42 \pm 0.63$ & 0.95 \\
Platelet count lakhs $/ \mathrm{mm}^{3}$ & $2.07 \pm 0.372$ & $2.07 \pm 0.36$ & 0.98 \\
Bleeding time (min) & $3.64 \pm 0.38$ & $3.63 \pm 0.38$ & 0.90 \\
Clotting time (min) & $4.29 \pm 0.50$ & $4.31 \pm 0.49$ & 0.74 \\
International normalized & $1.06 \pm 0.06$ & $1.06 \pm 0.06$ & 1.00 \\
$\quad$ ratio & $32.10 \pm 1.68$ & $32.16 \pm 1.59$ & 0.76 \\
Urea (mg/dl) & $1.01 \pm 0.10$ & $1.02 \pm 0.09$ & 0.86 \\
Creatinine (mg/dl) & & & \\
\hline
\end{tabular}

Table 3 Comparison of post-operative laboratory parameters

\begin{tabular}{llll}
\hline & Case $(n=162)$ & Control $(n=162)$ & $p$ value \\
\hline Haemoglobin $(\mathrm{gm} / \mathrm{dl})$ & $10.11 \pm 1.39$ & $8.99 \pm 1.00$ & 0.00 \\
Total count $/ \mathrm{mm}^{3}$ & $5.58 \pm 0.95$ & $5.59 \pm 0.95$ & 0.926 \\
Platelet count lakhs $/ \mathrm{mm}^{3}$ & $1.78 \pm 0.372$ & $1.17 \pm 0.114$ & 0.00 \\
Bleeding time (min) & $4.02 \pm 0.18$ & $6.00 \pm 0.44$ & 0.00 \\
$\begin{array}{l}\text { Clotting time (min) } \\
\begin{array}{l}\text { International normalized } \\
\text { ratio }\end{array}\end{array}$ & $5.01 \pm 0.157$ & $7.64 \pm 0.694$ & 0.00 \\
\hline
\end{tabular}

statistically significant $(p<0.01)$. Similar differences were found in fresh frozen plasma $(0.02 \pm 0.01$ vs. $0.43 \pm 0.98$, $p<0.01)$ and platelets $(0.02 \pm 0.01$ vs. $0.39 \pm 0.94, p<0.01)$ units transfused per patient (Table 4). There was no incidence of any adverse reaction during removal and transfusion of autologous blood.

Owing to the better post-operative profile (laboratory investigations, inotropic support and less ICU stay) of the patients in the autologous group, considerable differences were also found between the two groups in terms of post-operative morbidities (fever, wound infection, re-intubation and mediastinitis). In group 1 , only one patient $(0.6 \%)$ had fever and wound infection, whereas in the control group, eight patients $(4.9 \%)$ had fever and wound infection. Eight patients (4.9\%) in the control group had to be re-intubated in the post-operative period because of post-operative low cardiac output. All these differences were found to be statistically significant. None of the patients in either group had mediastinitis. None of the patients in either group had any transfusion reaction (Table 5).

There were five mortalities ( $3 \%$ ) in the control group and single mortality $(0.6 \%)$ in the autologous group due to low cardiac output. The difference was found to be statistically significant $(p<0.01)$ (Table 5).

\section{Discussion}

Many studies have been published in literature documenting techniques for the normalization of platelet and coagulation

Table 4 Comparison of mediastinal drainage and transfusion requirement

\begin{tabular}{llll}
\hline & Control $(n=162)$ & Cases $(n=162)$ & $p$ value \\
\hline $\begin{array}{l}\text { Mediastinal drainage (ml) } \\
\text { Packed red blood cell }\end{array}$ & $0.06 \pm 0.24$ & $2.1 \pm 0.63$ & $<0.01$ \\
$\quad$ (units/patient) & $0.02 \pm 0.01$ & $0.43 \pm 0.98$ & $<0.01$ \\
$\begin{array}{l}\text { Fresh frozen plasma } \\
\quad \text { units/patient) }\end{array}$ & $0.02 \pm 0.01$ & $0.39 \pm 0.94$ & $<0.01$ \\
$\begin{array}{l}\text { Platelets (units/patient) } \\
\text { Cost }\end{array}$ & 371 & 2495 & $<0.01$ \\
\hline
\end{tabular}


Fig. 1 Bar diagram showing comparison of post-operative ICU data between cases and controls

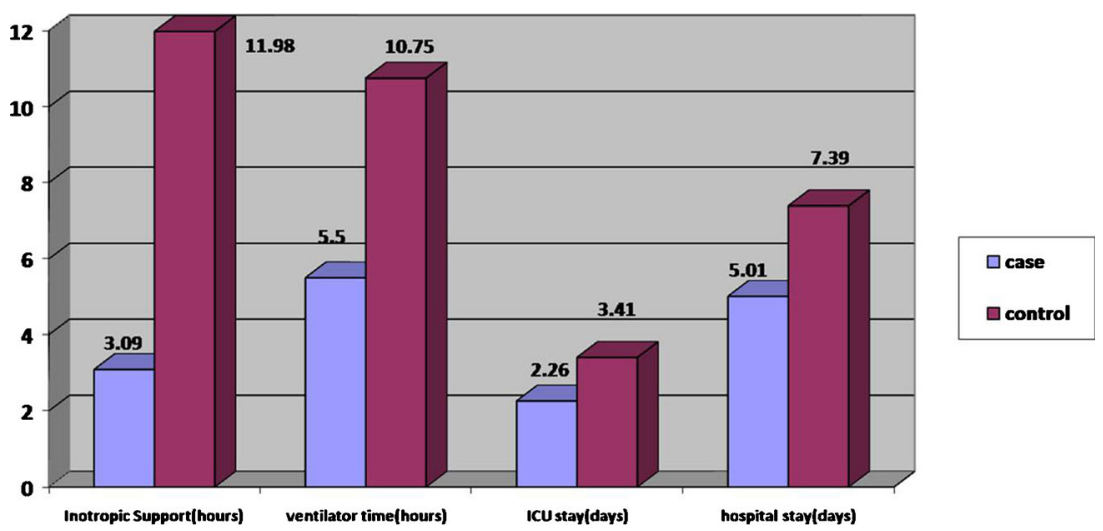

parameters, the reduction in post-operative bleeding and the decrease in homologous transfusion requirement after CPB. However, results have been inconsistent. Improvements in platelet number, platelet function, post-operative bleeding and transfusion requirement have been reported by some investigators, but others have not found these benefits [4-7]. Further analysis reveals that although these conflicting results are partly attributable to differences in study design, they are also due to inconsistent and often suboptimal application of the IAD technique itself.

In this study, we observed that the reinfusion of pre-bypass collected autologous blood reduced the post-operative blood loss, lessened the blood requirements, improved postoperative coagulation profile and avoided the use of any donor blood products in most $(82.1 \%)$ of the patients undergoing various open heart procedures. The use of autologous blood significantly augmented the post-operative platelet count in our patients. Our findings are in agreement with the findings of Kaplan et al. [8] and Lawson et al. [9] who also found higher platelet counts in their pre-donated patients. These findings emphasize an important finding that the reinfusion of fresh autologous blood increases the number of platelets in the circulating blood post-operatively because the aggregation or adhesion of these platelets to the foreign surface of the extracorporeal circuit is prevented [10].

Other investigators have noticed that the normal coagulation parameters are restored with the reinfusion of pre-donated

Table 5 Post-operative morbidity and mortality

\begin{tabular}{llll}
\hline & $\begin{array}{l}\text { Group I, case } \\
(n=162)\end{array}$ & $\begin{array}{l}\text { Group II, control } \\
(n=162)\end{array}$ & $\begin{array}{l}p \text { value (Pearson } \\
\text { chi-square test) }\end{array}$ \\
\hline Fever & $1(0.6 \%)$ & $8(4.9 \%)$ & 0.00 \\
Wound infection & $1(0.6 \%)$ & $8(4.9 \%)$ & 0.00 \\
Re-intubation & 0 & $8(4.9 \%)$ & 0.00 \\
$\begin{array}{l}\text { Mediastinitis } \\
\begin{array}{l}\text { Blood transfusion } \\
\text { reaction }\end{array}\end{array}$ & 0 & 0 & - \\
\begin{tabular}{l} 
Mortality \\
\hline
\end{tabular} & $1(0.6 \%)$ & $5(3 \%)$ & - \\
\hline
\end{tabular}

blood [8]. Furthermore, the use of pre-donated platelets is also likely to protect against the agonistic effect resulting from plasmatic blood contact activation in the extracorporeal circuit, thus qualitatively preserving the pre-donated platelets. In our study, we routinely measured the coagulation parameters (bleeding time, clotting time and international normalized ratio) and found a significant difference between the two groups. The results of our study are largely supported and are in conjunction with the study by Schonberger et al. [5] who studied the effect of intra-operative pre-donation on blood conservation in 100 patients of coronary artery bypass grafting. In contrast to the findings of Starr et al. [11], the reinfusion of pre-donated blood reduced the need for banked blood products in our patients. This can be explained by our study design. In our study, different groups were wellbalanced with respect to variables such as sex, body surface area and pre-operative blood haemoglobin content, all of which influence the usage of donor blood products [6].

Reinfusion of pre-bypass donated autologous blood has been shown to reduce post-operative blood loss and allogenic transfusion requirements and improve platelet count [12]. The improved haemostasis observed after fresh whole blood administration is related to the large, potent platelets that remained in the packed red blood cells and were not separated to the platelet-rich plasma during standard platelet concentrate preparation. This fact supports our finding of significant reduction of mediastinal drainage in our study group (234.38 vs. $562.47 \mathrm{ml}, p<0.01)$. The post-operative haemoglobin was significantly higher in the pre-donated patients than in the control patients owing to better coagulation profile and decreased mediastinal drain output. This facilitated the restoration of myocardial metabolism and minimized anaerobic glycolysis after bypass in these patients [13]. This was probably the reason why our pre-bypass donated patients required significantly less inotropic support than our control group.

The lowest safe level of anaemia has never been definitively established, and transfusion triggers used during CPB by surgeons and institutions differ widely. Clinical data regarding tolerance to anaemia during CPB are largely anecdotal [3] but point to a lower acceptable hematocrit level of $15 \%$. Because 
the heart is relatively protected during $\mathrm{CPB}$, other organs such as the brain serve as better markers of the adequacy of oxygen delivery. It has been our clinical experience that a hematocrit during CPB of $18 \%$ is well-tolerated, and we routinely use this number as the trigger for red blood cell transfusion during $\mathrm{CPB}$ employing moderate hypothermia. Bracey et al. [14] in a randomized trial of a restrictive transfusion threshold of $8 \mathrm{~g} / \mathrm{dl}$ versus a liberal threshold of $9 \mathrm{~g} / \mathrm{dl}$ demonstrated no detrimental effect of a restrictive threshold. Hebert et al. [15] conducted a prospective, randomized, controlled trial to determine the outcome of a transfusion protocol that maintained haemoglobin level at 7 to $9 \mathrm{~g} / \mathrm{dl}$ (strict protocol) or at $10 \mathrm{~g} / \mathrm{dl}$ or more (liberal protocol). They reported that there was no overall difference in mortality between the two groups and that a restrictive protocol was at least as effective and possibly superior to the liberal transfusion protocol. In our clinical experience, a post-operative haemoglobin of $8 \mathrm{~g} / \mathrm{dl}$ or more is well-tolerated, and we routinely used this transfusion trigger post-operatively.

A summary of 24 studies evaluating the effects of blood transfusion on outcomes in cardiac surgical patients was presented by Murphy and Angelini [16] in their review of indications of blood transfusion in cardiac surgery. All of the studies broadly agreed in their conclusions that blood transfusion is associated with increased peri-operative and long-term mortality including stroke, delirium, renal dysfunction and failure, deranged liver function, bacteremia, surgical site infection, prolonged ventilation time and prolonged intensive care unit and hospital stays. In agreement with these studies, we also found that our control group (with higher transfusion rate per patient and percentage patients transfused) had significantly high ventilator time, prolonged ICU and hospital stay, increased wound infection and fever and significantly high serum urea and creatinine and liver enzymes compared to the study patients. Similar findings were reported by Fransen et al. [17] in their multivariate analysis identifying packed red blood cell (PRBC) transfusion as the strongest predictor of adverse post-operative outcome.

The majority of studies achieving very low transfusion rates used low to low-moderate transfusion triggers both during and following CPB $[6,7,18]$. Conversely, the studies reporting high rates of transfusion either used higher transfusion triggers or the triggers were not stated, indicating that the investigators likely did not recognize or place enough emphasis on this essential blood conservation measure [19]. Finally, the studies that achieved overall transfusion rates of less than $30 \%$ used the cornerstones of blood conservation like pre- or intra-operative autologous blood donation, nonblood priming, return of residual circuit blood to the patient, low or moderately low intra- and post-operative transfusion triggers and return of mediastinal shed. We followed the same principles of blood conservation except for return of mediastinal shed and achieved a transfusion rate of $6.2 \%$ and
0.06 units/patient with a transfusion trigger of $18 \%$ hematocrit on $\mathrm{CPB}$ and haemoglobin of $8 \mathrm{~g} / \mathrm{dl}$ post-operatively. Our results are in conjunction with the landmark studies on acute normovolemic hemodilution by Cosgrove et al. [6] and Ovrum et al.[7].

Although the safety of the blood transfusion has increased in recent years, a major fear is the risk of transmittable viral infections and transfusion reactions [2]. The goal of transfusion-free cardiac operations is appealing to patients and promotes health-care cost containment. The direct cost for processing a unit of packed red blood cells/FFP/platelets at our institution is US\$20. In contrast, the cost of the tubing and blood bag used for intra-operative autotransfusion is US\$5.0. The average cost of transfusion per patient was US\$7.0 in the study group and US\$50.0 in the control group.

Sarin et al. [20] reported increased post-operative morbidity and mortality in their non-autologous group due to increased allogenic blood transfusion. In agreement to these findings, we also found that our control group had higher post-operative morbidity and mortality.

The effects of blood transfusion on the functions of the immune system have been studied in humans and laboratory animals for more than 25 years. It is becoming customary to refer to these effects on the immune system as 'immunomodulatory', as they may involve augmentation as well as suppression of elements of the immune response. Clinically, the results of these actions lead to poor outcome in patients who have received allogeneic blood. These effects may be abrogated by the use of syngeneic or autologous blood or leukodepleted allogeneic blood components [21]. Our study has supported this finding.

To conclude, the use of intra-operative pre-donation improves haemostasis, decreases the post-operative blood loss and improves the post-operative outcome in terms of ICU and hospital stay, morbidity and mortality. Intra-operative autologous blood pre-donation has been proved as a safe and very efficacious technique for blood conservation after cardiopulmonary bypass and should form an important part in the blood conservation techniques in cardiac surgery.

This simple technique is safe, efficacious and cost-effective and reduces the patient's exposure to possible complications of homologous blood transfusion.

\section{References}

1. Dodrill FD, Marshall N, Nyboer J, Hughes CH, Derbyshire AJ, Stearns AB. The use of the heart-lung apparatus in human cardiac surgery. J Thorac Surg. 1957;33:60-73.

2. Huggins C. Hazards of transfusions and ways to reduce their risk: blood conservation. Transplant Proc. 1989;21:43-4.

3. Cosgrove DM, Amiot DM, Meserko JJ. An improved technique for autotransfusion of shed mediastinal blood. Ann Thorac Surg. 1985;40:519-20. 
4. Hallowell P, Bland JHL, Buckley MJ, Lowenstein E. Transfusion of fresh autologous blood in open-heart surgery: a method for reducing bank blood requirements. J Thorac Cardiovasc Surg. 1972;64:941-8.

5. Schonberger JP, Bredee JJ, Tjian D, Everts PA, Wildervuur CR. Intraoperative predonation contributes to blood saving. Ann Thorac Surg. 1993;56:893-8.

6. Cosgrove DM, Thurer RL, Lytle BW, Gill CG, Peter M, Loop FD. Blood conservation during myocardial revascularization. Ann Thorac Surg. 1979;28:184-9.

7. Ovrum E, Holen EA, Linstein MA. Elective coronary artery bypass without homologous blood transfusion. Scand J Thorac Cardiovasc Surg. 1991;25:13.

8. Kaplan JA, Cannarella C, Jones EL, Kutner MH, Hatcher Jr CR, Dunbar RW. Autologous blood transfusion during cardiac surgery: a reevaluation of three methods. J Thorac Cardiovasc Surg. 1977;74:4-10.

9. Lawson NW, Ochsner JL, Mills NL, Leonard GL. The use of hemodilution and fresh autologous blood in open-heart surgery. Anesth Analg. 1974;53:672-83.

10. Van Oeveren W, Harder MP, Roozendaal KJ, Eijsman L, Wildevuur CRH. Aprotinin protects platelets against the initial effect of cardiopulmonary bypass. J Thorac Cardiovasc Surg. 1990;99:788-97.

11. Starr NJ. Con: blood should not be harvested immediately before cardiopulmonary bypass and infused protamine reversal to decrease blood loss following cardiopulmonary bypass. J Cardiothorac Anesth. 1990;4:522-5.

12. MohrR, Goor DA, Lavee J. Chapter8: Management of bleeding after open heart surgery: non pharmacological and topical means. In: MohrR, GoorDA, Lavee J, eds. Austin, Texas: R.G. Landes Company 1997: 131-175.
13. Weisel RD, Charleswoth DC, Mickleborough LL, et al. Limitations of blood conservation. J Thorac Cardiovasc Surg. 1984;88:26-38.

14. Bracey AW, Radovancevic R, Riggs SA, et al. Lowering the hemoglobin threshold for transfusion in coronary artery bypass procedures: effect on patient outcome. Transfusion. 1999;39:1070-7.

15. Hebert PC, Wells G, Blajchman MA, et al. A multicenter, randomized, controlled clinical trial of transfusion requirements in critical care. Transfusion Requirements in Critical Care Investigators, Canadian Critical Care Trials Group. N Engl J Med. 1999;340: 409-17.

16. Murphy GJ, Angelini GD. Indications for blood transfusion in cardiac surgery. Ann Thorac Surg. 2006;82:2323-34.

17. Fransen E, Maessen J, Dentener M, Senden N, Buurman W. Impact of blood transfusions on inflammatory mediator release in patients undergoing cardiac surgery. Chest. 1999;116:1233-9.

18. Jones JW, Rawitscher RE, McLean TR, Beall AC, Thornby JI. Benefit from combining blood conservation measures in cardiac operations. Ann Thorac Surg. 1991;51:541-6.

19. Tobe CE, Vocelka C, Sepulvada R, et al. Infusion of autologous platelet-rich plasma does not reduce blood loss and product use after coronary artery bypass: a prospective, randomized, blinded study. J Thorac Cardiovasc Surg. 1993;105:1007-13.

20. Sarin E, Speir A, Henry L, et al. Acute normovolemic hemodilution decreases blood product use and post-operative mortality and morbidity following cardiac surgery. J Am Coll Cardiol. 2012;59:e1843.

21. Chen G, Zhang F, Gong M, Yan M. Effect of perioperative autologous versus allogeneic blood transfusion on the immune system in gastric cancer patients. J Zhejiang Univ Sci B. 2007;8:560-5. 